\title{
Article \\ Use of Analogy in the Development of Intercultural Competence
}

\author{
Yuko Abe
}

International Liberal Arts Department, Akita International University, Akita 010-1211, Japan; yukoabe@aiu.ac.jp; Tel.: +81-18-886-5913

Received: 29 November 2018; Accepted: 7 May 2019; Published: 22 May 2019

check for updates

\begin{abstract}
Analogy is defined in many different ways. In this paper it is understood as a process in which the familiar structure of a direct experience in one situation is used to make conclusions regarding an expected experience within another structure. This process is based on the perceived similarity of the structures, not on rational, theoretical analysis of the relations between their components and the mechanisms of their interactions. The use of analogy relies on the engagement of intuitive recognition of the structural similarity between different instances of experience. The engagement of intuition does not preclude rational study and the development of strategies for using analogy, as part of this work focuses on rational learning about our own experience. Analogy plays two very different roles in this paper; as the main subject of this study, which focuses on the development of intercultural competence, and as a methodological instrument for carrying out and sharing the results of this study.
\end{abstract}

Keywords: analogy; competency development; intercultural competence; intercultural communication

\section{Introduction}

One of the most important goals of study abroad exchange programs for university students is to provide participants with the opportunity to develop intercultural communication competence (ICC) [1,2]. ICC, more recently called intercultural competence in recognition of a slightly more general context, is defined in many, not necessarily consistent ways [3]. At this point we define it as the ability to study, work, and live in a social environment with people with diverse cultural backgrounds. The issue of a definition is returned to later in this paper. It is commonly assumed by administrators of study abroad programs that immersing students in a multicultural environment provides an intercultural experience that is sufficient for the development of intercultural competence.

However, host institutions do not always provide a multicultural environment. Moreover, even so-called highly internationalized universities with an international student body cannot be considered fully representative of an authentic multicultural environment. For instance, universities create many mechanisms for eliminating sources of intercultural conflicts; students from similar cultural backgrounds tend to form homogeneous groups shielding them from exposure to other cultures and students may focus on their relatively short term educational goals rather than participate in intercultural experiences. To experience authentic intercultural encounters, students should be immersed in the life of nonacademic communities at large, but even this can limit their experience to only one culture of the host country. Thus, typically study abroad programs provide students with experience of intercultural interactions with only one culture. The difference between experience in one foreign culture and experience of living and working in a multicultural environment or in changing cultural environments is of special concern in this paper and was also considered important in previous literature on the subject. S.A. Stadler introduced the terminological differentiation of the "culture-specific intercultural competence" and the "culture-generic intercultural competence" [4]. 
Since it is the actual experience of intercultural interactions that matters, the extension from one foreign culture to other cultures by theoretical generalization is entirely ineffective. Therefore, the merit of studying abroad could be questionable. There would be no reason to travel abroad because a student could stay home and read books about other cultures.

The main objective of this paper is to demonstrate that the preferred tool in preparation for multicultural interactions is analogy-the method of transferring experience of that which is particular (individual experience derived from immersion in one particular culture) to the context of other particular, individual experiences. It is also proposed that access to this tool is provided by the development of an understanding of how we perceive and experience our environment.

This paper starts with an explanation of the concept of analogy. Then, the use of analogy is explained both as the subject of this paper and as its methodological tool. Finally, some specific examples providing support for the development of competency are presented as the basis for the use of analogy in its extension to other contexts.

\section{Analogy as a Subject and as a Tool}

This study focuses on the use of analogy in the preparation of students for their future intercultural encounters, but it may serve the more general objective of extending this preparation to any unfamiliar environment. However, it is important to prevent misunderstanding of this objective. This paper proposes an alternative to providing students with theoretical knowledge, but this does not mean that this theoretical knowledge does not have value.

The main objective of this article is to provide an alternative strategy for the development of competence and skills in overcoming the challenges of a novel environment, complementing existing methods. In this paper, the strategy is exemplified by the development of ICC, for which this novel environment means foreign culture. However, this special case can be used as a model for a much wider variety of novel environments of different types.

It should be emphasized that the concept of analogy is understood in many different ways and only one is chosen for this paper. Analogy, in this paper, is understood as a process where the familiar structure of a direct experience in one situation is used to make conclusions regarding the expected experience within another structure, on the basis of the perceived similarity of the entire experience, rather than on a rational, theoretical analysis of the relations between their components and the mechanisms of their interactions.

This does not mean that theoretical analysis and its increased level of abstraction is not important, but that a competent action in the context of a cultural environment, or more generally of any environment, is one which can be carried out without any support of rational thought or awareness. Someone who can speak without grammatical errors is not considered a competent speaker of the language if this is achieved by constant conscious reference to general rules. In the same way, someone who cannot avoid reference to prescribed theoretical rules of conduct in a foreign culture, or some other novel situation, should not be called competent.

On the other hand, there should be an awareness of the limited reliability of analogy in the transition from a past experience in one culture to potential interactions with other cultures. For instance, there should not be an attempt to transfer a former experience directly to the new cultural context, instead, surprising and unexpected aspects of the earlier encounter should be used as preparation for new surprises. We can learn more about ourselves and our own reactions in order to cope with all that we cannot predict or learn in advance in a new cultural environment. This is where analogy enters.

Analogy relies on the holistic perception of a similarity in complex systems with a large number of components with their own properties and mutual relations, not on the abstract elimination of secondary properties in the search for essential properties which are the subject of objective universal rules. This holistic perception is achieved at the subconscious level, apparently in an instantaneous act of recognition without any self-awareness. 
There is a legitimate question whether this type of process, which is dependent on the intuitive perception of similarity outside of rational control, can be the subject of a rational, academic study. Can we find general rules for the development or fostering of this type of competency? There is some support for this idea. We can find it in very old teachings-for instance, in the famous motto of the Delphic Oracle, written in the forecourt of the Temple of Apollo: "Know thyself" ( $\gamma v \tilde{\omega} \theta \iota \sigma \varepsilon \alpha v \tau o ́ v)$. Of course, the rule is not about the rational, theoretical knowledge of one's own psychology, but about the ability to recognize and intuitively interpret one's own subjective experience. An understanding of our own experience can help us understand others who may have very different cultural backgrounds and it can also help us to predict our reaction to unfamiliar situations. Even more importantly, it can give us access to intuitive resources, such as the recognition of similarities and the building of analogies, which escape rational analysis.

Finally, analogy, as it is defined and explained above, is not only a concept fundamental to the subject of this paper (focusing on the development of ICC), but is also utilized as a methodological tool for carrying out and sharing the results of this study. One particular case is presented, outlining the experience of supporting students in their development of ICC. Then the reader is invited to exercise his or her skills in the use of analogy to transmit this very strongly context-dependent structure to his or her own context.

\section{An Example of Intercultural Competence}

The method of extending familiar experience to novel contexts requires the skill of observation, not only of the environment, but also of our own experience within this environment. An elaborate, or at least adequate description of the familiar structure is required to use analogy as a research tool. This description does not have to be focused on analytical elements, but rather on a synthesis of that which gives the sense of familiarity of the context. It should describe the experience rather than look for commonalities or generalizations. Then we can try to identify the analog structures or situations.

The research field of the study is at Akita International University (AIU). AIU is a liberal arts institution with a student population of about 1000. It is located in Akita prefecture on the Northern seaboard of Honshu, the main island of Japan. It is a very young and small university in a rural area, but it is considered one of the most internationalized universities in Japan. This is because from the beginning it adopted a set of dynamic policies such as teaching all courses in English, requiring all students to study abroad for a year, and recruiting approximately one-fourth of the students on campus as international exchange students who live on campus together with Japanese students. AIU has achieved success in providing students with an international environment, an intercultural experience, and linguistic opportunities fitting their educational goals. The question remains as to what extent AIU students have achieved authentic ICC beyond mere familiarity with the culture of the country in which they studied abroad.

To present a complete picture of the situation, it is necessary to explain why intercultural competence is considered important at AIU and in Japan. Also, we should consider the rationale for the study abroad program and its emphasis on the development of intercultural competence. Because of the lengthy recession of the Japanese economy and the fact that Japanese students' English skills were far behind those of students in other developed countries [5], the Japanese government and the Japanese business world put emphasis on fostering "global human resources", which were defined as human resources with a global perspective, the development of a global network, and the ability to operate globally. According to the Ministry of Economy, Trade, and Industry (METI), these types of human resources were indispensable in order to secure a competitive advantage [6]. In addition, METI set the three types of "Common Global Competencies" which were identified as (1) fundamental competencies for working people, (2) communication skills in English, and (3) intercultural understanding competencies and leveraging [6]. Internationalization of universities was recognized as one of the most urgent issues and the government put considerable 
effort into promoting it, which explains the emphasis on this aspect of education at AIU and the high recognition of AIU in Japan.

Governmental policies are general and do not specify the meaning of ICC, but there is extensive literature on the subject.

ICC was sometimes defined in a very general, but not very useful way as "behavior that is appropriate and effective in a given context" [7]. There were also more precise definitions, such as "the overall internal capability of an individual to manage key challenging features of intercultural communication: namely, cultural differences and unfamiliarity, intergroup posture, and the accompanying experience of stress" [8] or "the ability to analyze the given social environment and select the appropriate behavior" [9].

The opportunity to develop ICC is one of the reasons for the increasingly popular study abroad exchange programs in a majority of universities not only in Japan, but also all over the world. For instance, the Council of Europe (Common European Framework of Reference for Languages) promotes intercultural skills, which are understood as the ability to bring the culture of origin and the foreign culture into relation with each other; cultural sensitivity and the ability to identify and use a variety of strategies for contact with those from other cultures; the capacity to fulfil the role of cultural intermediary between one's own culture and the foreign culture and to deal effectively with intercultural misunderstanding and conflict situations; and the ability to overcome stereotyped relationships $[10,11]$.

Recognition of the importance of ICC for economic and political national interests stimulated further research in the subject. ICC was frequently generalized to "intercultural competence" or "global and intercultural competence". For the present paper, the most important development in the study of intercultural competence was the discussion of whether intercultural competence can be learned. There is a quite extensive body of literature with arguments for the developmental character of intercultural competence, linking it with experiential processes requiring an extended period of time [12]. This is consistent with the idea proposed in this paper to use an alternative approach utilizing analogy.

It is frequently assumed that participation in the study abroad program automatically brings multicultural experience sufficient for the development of intercultural competence. However, as it was mentioned above in the Introduction, host institutions of exchange programs for students usually cannot provide a real multicultural environment conducive for the development of intercultural competence. Even the most internationalized universities cannot provide exposure to a variety of cultures without the restriction to their academic and therefore artificially homogenized versions. This brings about the challenge to develop strategies for the development of ICC transcending the limitations of bilateral exchanges of students.

Research on the development of ICC and its use in pedagogical practice focused on the effectiveness of existing methods with a gradual transition to exploring alternative, more effective methodologies [13]. It is easy to recognize the limitations of an approach emphasizing adaptation, as expressed in the traditional saying "When in Rome do as the Romans do", as well as the limitations of passive observation as a way to learn about other cultures. These limitations prompted a move toward more active forms of engagement for students in activities carried out together with local communities. The transition to a more active style of learning brought an improvement in ICC, but could not overcome the limitations of learning through interaction with only one particular culture of a host country.

In this research, to assess the effectiveness of their experience abroad, students were interviewed and asked to reflect on what they had learned. It was realized that the method of study itself could be an instrument of further improvement. Students who reflected on their experiences and their transformation through these experiences could achieve the goal of being better prepared for future intercultural encounters. This was the source of the idea to utilize self-reflection and self-study as a way to go beyond the particular, but rather accidental location of experiences abroad.

In the following, the examples will illustrate the use of self-reflection, i.e., learning about ourselves, as a tool for transcending the limits of individual experience within one culture. The examples consist 
of fragments of interviews with students, in which we can easily recognize growing understanding of their own experience. It has to be emphasized that the role of these interviews within the present paper is not to provide empirical evidence for the general thesis of the paper, but to illustrate it in a very specific context. Most importantly, students were not asked directly to comment on own experience, but rather to reflect on what they learned. Students spontaneously focused on their own reactions and their transformation.

Examples 1 and 2 are examples of the development of empathy, which is an important element in building successful communication.

Example 1. "Before going to year abroad, I wanted to talk to international students, but I couldn't because I was shy and my English was not good. But when I was in the US and felt really lonely, I was so glad somebody talked to me especially when they showed the interests about Japanese culture, I felt very happy, so when I returned to Japan, I am trying to talk to the international students much more than before. Also I try to ask about their countries".

Example 2. "Before going to year abroad, when international students asked me questions, or somebody had problems, then, I offered my SUPPORT. I thought it was rather too much if I offered help without being asked. However, after experience in living abroad, I learned it was not easy to ask for help in the unfamiliar country. I did not speak their language and they did not care about foreigners. After having this experience, I try to speak to international students from my side as much as possible".

Examples 3, 4, and 5 show growing understanding of students' cultural identity; their "Japaneseness".

Example 3. "Before going to year abroad, I always look outside of Japan, for me to be a global citizen and internationalized person means to be westernized. During the time of year abroad, I realized I am Japanese, and I can't be American, or European. Now I think I must develop my internationalized identity on the top of my Japanese identity. That is the real global citizenship".

Example 4. “When I was in one year abroad program, I was so ashamed that I couldn't answer the questions about Japan and realized how little I know about my own country. For them I am a representative of the Japanese, but I didn't know anything. Even though I can speak good English, it is not good enough".

Example 5. "I felt I am Japanese when I behaved or reacted different way from other people from different countries. I didn't know how much I missed all Japanese things. I am surprised myself to feel like this, but I am proud that I am Japanese".

This growing understanding of one's own experience is only one step away from achieving an extension by analogy to unfamiliar situations. The examples above were not prompted. Students did not have any instruction or even suggestions as to how to reflect on their experiences. The actual method of using analogy should provide some tools for developing better methods of exploration and greater understanding of one's own experience. At present, suggestions addressed to students are limited, but have the potential to be extended. Recommendations include working on the following to help students develop their:

1. ability to observe the environment and their own experiences without prejudice or preconception;

2. ability to be aware of their own emotions and feelings, to explore their own possibly irrational, emotional side;

3. ability to empathize with other people;

4. ability to engage in interaction with other people;

5. skills in expressing their own feelings and experiences; 
6. improvement in relying on their intuitive sense of similarity between experiences;

7. ability to use self-reflection for understanding others.

\section{Conclusions}

The strategy for the development of ICC presented in Section 3 does not address directly a more general reflection of the role of analogy in building any type of competence described in Section 2 . However, once the ability to utilize our intuitive skills is developed, the recognition of analogy between different structures of our experience does not require any intellectual, rational effort, such as is required for a higher level of abstraction and the accumulation of knowledge of multiple cultural environments. This ability consists of supporting, not suppressing our intuition. The key to the successful use of the wisdom in the motto of the Delphic Oracle "Know thyself" is in the recognition of the role of self-reflection in building analogy between structures of our experience.

The experience presented in Section 3, without any pretense to generality or objective validity, may become valuable for someone who will find an analogy between the structure of the experience and the context of his or her own experience.

Funding: This research received no external funding.

Conflicts of Interest: The author declares no conflict of interest.

\section{References}

1. Yokota, M.; Ohta, H.; Shimmi, Y. (Eds.) Impact of Study Abroad on Career Development and Life; Gakubunnsha: Tokyo, Japan, 2018.

2. Adachi, T. Purposes and Benefits of Undergraduate Study Abroad Programs and Their Place within the Curriculum. Toyo Eiwa J. Humanit. Soc. Sci. 2010, 28, 77-91.

3. Fantini, A.E. Assessing Intercultural Competence: Issues and Tools. In The SAGE Handbook of Intercultural Competence; Deardorff, D.K., Ed.; Sage Publications: New York, NY, USA, 2009; pp. 456-476.

4. Stadler, S.A. Which Competence? A Comparative Analysis of Culture-specific vs. Culture-generic Intercultural Competence Development. Adv. Econ. Bus. 2017, 5, 448-455. [CrossRef]

5. Test and Score Data Summary for TOEFL iBT Tests. Available online: http://www.ets.org/s/toefl/pdf/94227 unlweb.pdf (accessed on 20 February 2019).

6. PISA 2018 Global Competence. Available online: http://www.oecd.org/pisa/pisa-2018-global-competence. htm (accessed on 20 November 2018).

7. Spitzberg, B.H. A Model of Intercultural Communication Competence. In Intercultural Communication: A Reader, 9th ed.; Samovar, L.A., Porter, R.E., Eds.; Wadsworth: Belmont, CA, USA, 2000; p. 375.

8. Kim, Y.Y. Intercultural Communication Competence: A Systems-Theoretic View. In Cross-Cultural Interpersonal Communication; Thing-Toomey, S., Korzenny, R., Eds.; Sage Publications: Newbury Park, CA, USA, 1991; p. 259.

9. Samovar, L.A.; Porter, R.E.; McDaniel, E.R. Communication Between Cultures, 6th ed.; Wadsworth: Belmont, CA, USA, 2007; p. 314.

10. Council of Europe. Common European Framework of Reference for Languages: Learning, Teaching, Assessment; Cambridge University Press: Cambridge, UK, 2001; pp. 104-105.

11. Byram, M.S. From Foreign Language Education to Education for Intercultural Citizenship: Essays and Reflection; Multilingual Matters: Clevedon, UK, 2008.

12. Arasaratnam, L.A. Intercultural Competence. In Oxford Research Encyclopedia, Communication; Oxford University Press: Cary, NC, USA, 2016; pp. 1-20. Available online: http://oxfordre.com/communication/view/10.1093/ acrefore/9780190228613.001.0001/acrefore-9780190228613-e-68?print=pdf (accessed on 26 February 2019).

13. Abe, Y. Willingness to Support Community as a Consequence of Awareness Developed by Japanese Study Abroad Students—Focusing on the Sense of Community. Jpn. Lang. Educ. 2015, 50, 91-101.

(C) 2019 by the author. Licensee MDPI, Basel, Switzerland. This article is an open access article distributed under the terms and conditions of the Creative Commons Attribution (CC BY) license (http://creativecommons.org/licenses/by/4.0/). 